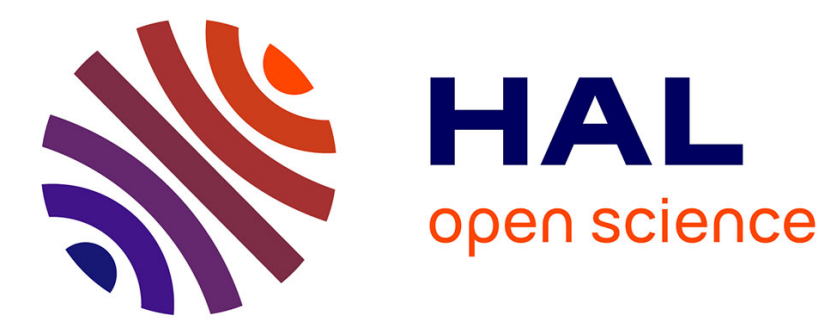

\title{
Categorization Deficit in Old Age: Reality or Artefact?
}

Valérie Pennequin, Roger Fontaine, Françoise Bonthoux, Agnès Blaye

\section{To cite this version:}

Valérie Pennequin, Roger Fontaine, Françoise Bonthoux, Agnès Blaye. Categorization Deficit in Old Age: Reality or Artefact?. Journal of Adult Development, 2006, 13, pp.1-9. 10.1007/s10804-0069000-5 . hal-00164329

\section{HAL Id: hal-00164329 \\ https://hal.science/hal-00164329}

Submitted on 20 Jul 2007

HAL is a multi-disciplinary open access archive for the deposit and dissemination of scientific research documents, whether they are published or not. The documents may come from teaching and research institutions in France or abroad, or from public or private research centers.
L'archive ouverte pluridisciplinaire HAL, est destinée au dépôt et à la diffusion de documents scientifiques de niveau recherche, publiés ou non, émanant des établissements d'enseignement et de recherche français ou étrangers, des laboratoires publics ou privés. 


\title{
CATEGORIZATION DEFICIT IN OLD AGE: REALITY OR ARTEFACT?
}

\author{
Valérie PENNEQUIN ${ }^{1}$, Roger FONTAINE ${ }^{1}$, \\ Françoise BONTHOUX ${ }^{2}$, Nelly SCHEUNER ${ }^{2}$, Agnès BLAYE ${ }^{3}$ \\ ${ }^{1}$ Laboratory of Experimental Psychology, UPRES 2114 "Aging and adult development: \\ cognition, rythmicity and adaptation "University of Tours, France. \\ 2 Laboratory of Psychology and NeuroCognition, CNRS UMR 5105, \\ University of Grenoble, France. \\ ${ }^{3}$ Center of Research in Psychology of Cognition, Language, and Emotion, EA 3273, \\ University of Provence, France
}

Valérie PENNEQUIN : Lecturer in Psychology

Roger FONTAINE : Professor in Psychology

Françoise BONTHOUX : Lecturer in Psychology

Nelly SCHEUNER : PostDoctoral position in Psychology

Agnès BLAYE : Professor in Psychology

Valérie PENNEQUIN

Maître de Conférences

Département de Psychologie

3 rue des tanneurs

B.P. 4103

37041 TOURS CEDEX 1

France

tel : 0247366721

ou 0247557910

e mail : pennequin@univ-tours.fr

Running head : Categorization deficit in old age : reality or artefact?

Key words : categorization, taxonomic relations, thematic relations, aging 
Abstract

When categorization behaviour is compared between young and elderly adults, results usually show a decrease in taxonomic choices along with an increase in thematic choices. This can be interpreted in two ways: a decline in the ability to perceive and use taxonomic relations, or a modification of conceptual preferences with aging related to a bias stemming from material which favours young adults. We evaluated the second hypothesis by studying whether the salience of categorical associations could explain the differences generally observed between young and elderly adults. This hypothesis was tested on 25 young subjects $(M=45.3$ years, $S D=5.6$ years $)$ and 30 elderly subjects $(M=71.5$ years, $S D=7.1$ years $)$ using a matching task: individual judgments were used to build triads in which a target was presented along with a strong and a weak associate. In line with our hypothesis, both age groups were influenced by associative strength and type of relation in the same way. Results are interpreted with Baltes's (1987) model. 
The ability to form categorical representations of the environment is a basic cognitive activity which allows us to reduce the complexity of the world in which we live. Categorization allows us to equate different objects on the basis of various criteria, and thereby move from the specific to the general. According to Sloutsky (2003), this type of activity is essential in most cognitive activities, such as perception, problem-solving and memory, for three reasons: first, with regard to cognitive resources it is more efficient to incorporate a potentially infinite number of individual objects into a smaller number of categories; secondly, categorizing allows knowledge of objects to be organized, particularly by creating hierarchies, which again makes processing less demanding cognitively; and finally, categorization enables induction processes, since members of a single category often possess unobserved common properties.

Among cognitive processes, aging effects on categorization behavior has been little studied. The few results available show a differential effect of aging depending on the type of categorical organization, i.e., taxonomic or thematic organization. Taxonomic relations refer to groupings of objects of the same kind belonging to a semantic category (i.e. dog and cat as animals), whereas thematic relations correspond to an organization of knowledge in terms of familiar scenes or events (i.e. dog and bone since the dog usually eats bones). Taxonomic organization is often considered as more elaborated, thus being acquired later (Nelson, 1983) and having a greater inductive power (Markman, 1989).

In older people, taxonomic categorization seems also to be less available than in younger adults. Categorical behavior is generally studied with two procedures. In the free sorting task, individuals are required to put together items, either objects or pictures that "go together well". In the matching-to-sample task, they have to choose which of two items "goes best" with the previously presented target. In both procedures, items are chosen to allow either a taxonomic or a thematic grouping.

When elderly people are asked to group drawings of common objects in any way they wish (free sorting paradigm), they are less likely than younger people to use taxonomic categories as criteria for grouping (Annett, 1959; Cicirelli, 1976; Fontaine \& Toffart, 2000; Kogan, 1974). Similarly, the results of Denney \& Lennon's developmental study (1972) showed that whereas middle-aged subjects (ranging in age from 25 to 55 years) tended to group the entire geometric stimulus array into piles of similar items, the elderly people group 
(ranging in age from 65 to 95 years) arranged only a portion of the stimulus array into elaborate designs. In matching to sample tasks, Smiley \& Brown (1979) have also observed a majority of thematic choices in the elderly when participants were instructed to match one of two objects with a target, but a majority of taxonomic choices in young adults. So, studies which compared the categorization skills of elderly persons with those of young adults reflect a decrease in the use of taxonomic relations after 60 years of age (in addition to an increase in the use of thematic relations in these experiments).

Two explanations could be proposed. The first assumes that the ability to perceive and use taxonomic relations declines (Annett, 1959; Cicirelli, 1976; Denney \& Lennon, 1972). To understand better the nature of this decline, learning studies were conducted. Results showed that the decline would be functional before 75 years of age since learning increased taxonomic categorization (Denney \& Denney, 1974), but would be structural after this age, being related to neuro-physiological modifications (Pennequin \& Fontaine, 2000). The second explanation refers to developmental changes in conceptual (Smiley \& Brown, 1979) or categorical (Fontaine \& Toffart, 2000) preferences, which would reflect the differential accessibility of taxonomic and thematic relations at a given age. This interpretation provides a more optimistic view of aging. However, the factors underlying the evolution of preferences are not clearly identified. For Kogan (1974), judicious selection of tasks can yield stylistic differences between age groups that are equally adaptive for both. Since elderly people are more prone than young adults to categorize thematically, they will have a disadvantage with stimuli in which thematic relations are not easily available. This author concluded that the attribution to older adults of regression in categorization behavior may be a consequence of the use of such stimuli. Generally, either the items cannot be categorized either taxonomically or thematically, or thematic relations are much less salient than taxonomic ones. For example, very few meaningful thematic relations were involved in Annett's (1959), Olver and Hornsby's (1967), and Denney \& Lennon 's (1972) stimuli. This potential stimulus bias was even more evident in studies involving geometrical blocks (Denney \& Lennon, 1972; Denney, 1974). The interrelations between geometrical blocks are mainly defined by perceptual similarities rather than by meaning or thematic content.

This study was aimed at testing the second assumption regarding aging effects on categorical behaviour. A related hypothesis was explored in young adults. In three recent experiments, Lin and Murphy (2001) attempted to replicate Smiley and Brown's (1979) 
findings of predominant taxonomic categorization in young adults, but they did not succeed. On the contrary, they showed that thematic categorization was very frequent in young adults (from $49 \%$ to $73 \%$ ). To explain their results, Lin and Murphy assumed that the relative salience of taxonomic and thematic relations affected category construction. In two subsequent experiments (Lin and Murphy, 2001), they tried to alter response preferences by emphasizing one kind of relation. Results showed that performing a similarity comparison task (Experiment 7) or a difference judgment task (Experiment 8) prior to each category construction enhanced taxonomic categorization. Lin \& Murphy's hypothesis, that the relative salience between taxonomic and thematic relations affects the way categories are formed and used, was therefore supported (see also Ross \& Murphy, 1999). Stemming from these experiments in young adults, we studied the salience of taxonomic and thematic relations to determine whether it could explain the differences generally observed between young and elderly adults.

The salience of categorical relations can be characterized by the associative strength between stimuli. Thematic relations among objects come mainly from individual experience with specific episodes in which these objects were involved. Therefore, association strength should be highly variable depending on the specific objects presented. On the other hand, taxonomic relations are likely to be formed on multiple bases: by extracting common properties among objects; perceptual and more abstract properties; and by noticing generic names. Associative strength should then depend on the hierarchical level of taxonomic categories since it is related to perceptual and non-perceptual similarity (Rosch, Mervis, Gray, Johnson \& Boyes-Braem, 1976). It should also depend on experience since common functional properties might be detected among objects that play a same role in a given event or scene (Nelson, 1983).

The effect of associative strength on recall, clustering, recognition or priming has been studied in adults (e.g. Cramer \& Eagle, 1972; La-Heij, Dirkx, \& Kramer, 1990; Lathey, 1979; Mathews, Maples, \& Elkins, 1981) and in children (Krackow \& Gordon, 1998; Nation \& Snowling, 1999; McCauley, Weil, \& Sperber, 1976). Priming effects depend on associative strength between words in adults and in children whatever the kind of categorical relation being considered (i.e. taxonomic or thematic). Hence, associative strength seems largely involved in automatic priming effects. Yet its effects in categorization tasks in which more controlled comparison processes are likely to be required are rarely explored. However, a 
recent study has shown the powerful influence of associative strength in making matching choices, thematic or taxonomic, in children aged 4 to 6 (Scheuner, Bonthoux, Cannard \& Blaye, 2004, in press). As underlined by Scheuner, matching task performances are generally, reported as mean percentages of taxonomic or thematic choices computed across subjects and items. From these means, conclusions can be drawn regarding the accessibility of taxonomic and thematic relations as a function of age and/or situation. Yet it is unlikely that:

a) 2 associates would be related equally to a given target (e.g. bone and dog vs. giraffe and dog).

b) all the associates of a same type (taxonomic or thematic) would be equivalent across targets (e.g. cat and tiger vs. bear and bird).

c) associative strength of a given associate would be judged equivalent by different subjects. According to individual daily experience, cat and dog would not have the same associative strength for individuals. Lin and Murphy (2001) also claimed that there could be uncontrolled differences between samples, which could explain the difference between their results and those previously observed in young adults, but did not test them.

Altogether, these considerations have led us to study at the individual level the relative effect of associative strength and type of relation, taxonomic or thematic, on adults' matching choices. We reasoned that if one associate is more strongly related to the target than the other one, its activation might be more automatic and might compete or interfere with the more controlled comparison process, which is supposedly required when choosing between several associates (Siegler, 1997). In addition, since associative strength depends on individual experience, it is highly probable that judgments of associative strength vary between individuals in a given age group, and also evolve with age. We explored whether this variable could help to understand the evolution of categorical choices in aging. Indeed, stimuli in categorization tasks are selected by the experimenter on the basis of his own intuitive judgments and are therefore unlikely to correspond to the judgments of adults from various age groups. Hence a decrease of taxonomic choices in elderly people might reflect the evolution of associative strength judgments rather than the evolution of categorical skills.

The study of the relative dominance of thematic or taxonomic relationships in aging is important because categorization is a process involved in most cognitive activities. In order to remedy deficits in these cognitive activities effectively, it is first necessary to understand the 
processes underlying these deficits. So, the aim of the study was thus to compare the relative effects of associative strength and type of relation on the categorical choices of young and older subjects. First, we assumed that the differences between young and elderly adults would decrease, or even disappear, if stimuli were chosen on the basis of individual judgments of associative strength. Second, in accordance with Lin and Murphy's results (Lin \& Murphy, 2001), we predicted an advantage for thematic relations in young and elderly adults when associative strength was controlled. Finally, in both age groups, we expected that individuals would choose predominantly the stimuli which were highly associated to the target and thematically related to it.

\section{Method}

\section{Participants}

Fifty-five adults participated in this study. The young subjects were 18 females and 7 males with ages ranging from 37 to 55 years $(M=45.3$ years, $S D=5.6$ years $)$. The elderly subjects were 21 females and 9 males with ages ranging from 64 to 81 years $(M=71.5$ years, $S D=7.1$ years). They were seen individually in a quiet room of their own home or in their sheltered accommodation. Neither senile dementia (Mini Mental Test above 27), nor health problems which could have impaired their intellectual performance were diagnosed. There was no significant difference between young and elderly subjects concerning their level of education $($ mean $=12.2$ years of formal education $)$.

\section{Stimuli}

Our material was inspired by that used in Scheuner et al.'s study (2004, in press). 66 black and white drawings of objects contained in a $7 \times 9 \mathrm{~cm}$ rectangle were used as stimuli: 11 targets and for each of them, 3 taxonomic and 3 thematic associates. All the associates were perceptually dissimilar to the corresponding target (less than 4 on a scale from 1 perceptually dissimilar - to 9 - perceptually similar - as judged by ten young adults).

The 3 taxonomic and the 3 thematic associates of a given target were chosen to correspond a priori to 3 levels of associative strength (strong, medium and weak). Taxonomic associates corresponded to 3 hierarchical levels. For instance, with the target "dog", the supposedly strongest associate (T1) was another dog, i.e. an exemplar from the same basic 
level category; the supposedly medium associate (T2) was a guinea-pig, i.e. an exemplar from the same slot-filler category of pets; and the supposedly weakest associate (T3) was a snake, i.e. an exemplar from the same superordinate category of animals (see Appendix 1). All the associates were perceptually dissimilar to the target in order to understand better what associative strength means in the case of taxonomic relations, independent of perceptual similarity.

Thematic associates were selected mostly on the basis of previous experiments (Scheuner, Bonthoux, Cannard \& Blaye, 2001, 2004 in press) using a similar methodology. There was a priori a strong associate (Th1), a medium associate (Th2) and a weak associate (Th3). We expected that T1, T2, T3 and Th1, Th2, Th3 would be judged with sufficient difference in associative strength to be able to extract a strong (+) and a weak (-) associate for each target and type of relation ( $\mathrm{T}$ and $\mathrm{Th}$ ) for each participant.

\section{Procedure}

Performances of young and old subjects were assessed in a matching task after they had judged in a previous session the associative strength between targets and several associated pictures. These judgments served to construct the sets of stimuli used in the matching task. It is worth noting that, in memory studies, associative strength corresponds to the production frequency of words in verbal association or exemplar generation tasks and thus is a measure of lexical association. Here, since the matching task involved pictorial stimuli, judgments of associative strength were made on pictures.

To show the influence of associative strength and type of relation on matching, each target was proposed along with 2 associated pictures of opposite strength in 2 types of configurations. In homogeneous configurations, both associates shared the same conceptual relation with the target (i.e. a strong and a weak thematic associate, $\mathrm{Th}+$ and $\mathrm{Th}-$, or a strong and a weak taxonomic associate, $\mathrm{T}+$ and $\mathrm{T}-$-). In heterogeneous configurations, conceptual relations differed (i.e. a strong thematic and a weak taxonomic associate, $\mathrm{Th}+$ and $\mathrm{T}-$, or a strong taxonomic and a weak thematic associate, $\mathrm{T}+$ and $\mathrm{Th}-)$. Subjects were required to choose the best match with the target. This instruction was selected because it was nonconstrained: since it did not specify whether the subject had to choose an object of the same kind as the target (taxonomically related) or an object of a different kind which belonged to 
the same event or scene as the target, we were able to observe how each individual spontaneously interpreted the task (Deak \& Bauer, 1995).

We reasoned that if matching choices were predominantly guided by associative strength, strong associates would be more frequently chosen than weak associates in all configurations. Alternatively, if both associative strength and conceptual relation had an influence on matching choices, then this result would still be observed in homogeneous configurations, but not in all heterogeneous configurations.

In sum, all adults participated in 2 successive sessions. In the first, they judged the associative strength of all the target-associate pairs. These ratings were analyzed to extract for each subject and each target a strong and a weak thematic associate (Th + and $\mathrm{Th}-)$ and a strong and a weak taxonomic associate ( $\mathrm{T}+$ and $\mathrm{T}-)$. In the second session, participants performed the matching task in which the strong and weak associates they had previously judged were contrasted.

\section{$\underline{\text { Session 1: Judgments of associative strength }}$}

There were 2 successive series of judgments. Participants first judged associative strength on a scale from 0 to 10 for all the target-associate pairs ( 6 judgments - T1, T2, T3 and Th1, Th2, Th3 - for each of 11 targets). The target was presented above the associate. The scale was analog to the pain scale used by physicians. The subject was asked: "could you show me with the cursor if both pictures go together very strongly (showing the top of the scale), moderately strongly (showing the middle of the scale) or not strongly (showing the bottom of the scale)". At the start of the session, an example of judgment was provided and a series of 12 judgments ( 2 targets $\mathrm{x} 6$ associates) served as familiarization trials not included in the analyses. During these trials, additional explanations were sometimes given. After this, the subject judged the remaining pairs ( 9 targets $\mathrm{x} 6$ associates) which were presented in a fixed pseudo-random order (a given target never appeared on 2 successive trials).

This spontaneous judgment phase was followed by a more constrained one to ensure that a strong and a weak associate could be extracted for each subject, target and type of relation. The 3 taxonomic or thematic associates were shown simultaneously with each corresponding target. The individual was required to order the 3 pictures as a function of their associative strength with the target. 
Spontaneous associative strength judgments were analyzed first. For each adult, when the 3 judgments (3 taxonomic or thematic associates for a given target) differed from each other by at least 1 point, weak and strong associates were chosen on the sole basis of the spontaneous judgments. Alternatively, when the 3 associates were judged to be equivalent (the difference between them was 0 or 1), and when 2 associates were judged equivalent and the third was clearly distinct, constrained judgments were used. In this case, participants were asked to order 3 thematic or 3 taxonomic associates of a target, being thus constrained to differentiate them. If both spontaneous and constrained judgments indicated the same strong or weak associate, constrained judgments were used to choose between the other two. From these analyses, a strong and a weak taxonomic associate ( $\mathrm{T}+$ and $\mathrm{T}-$-) and a strong and a weak thematic associate (Th+ and Th-) were selected for each subject and each target to be used in the following matching experiment.

\section{$\underline{\text { Session 2. Matching task }}$}

A week later, participants performed a picture matching task. In each trial, the target was shown first, followed by 2 comparison pictures associated to the target. Associates were placed side by side below the target. After pointing at the target (saying "see this one?"), the experimenter asked: "which one (pointing successively at the 2 comparison pictures) goes best with it?" Participants were told that there were no right or wrong answers, so they could select whatever choice seemed most sensible to them. After each choice, they were asked to justify it. A choice was considered as a taxonomic choice if the subject's justification was also taxonomic, i. e. if the subject said the name of the semantic category: for example, "I put the dog with the cat because they are both animals". If the subject made a taxonomic choice but with a thematic justification, "I put the dog with the cat because the dog chases the cat", the response was considered as a thematic choice.

In each trial, 2 associates were presented one strongly and the other weakly associated to the target. There were 4 configurations for each target. Two configurations were homogeneous: either 2 taxonomic associates $(\mathrm{T}+\mathrm{T}-)$ or 2 thematic associates $(\mathrm{Th}+\mathrm{Th}-)$ were contrasted. The other two configurations were heterogeneous, contrasting a taxonomic and a thematic associate (Th+T- and $\mathrm{T}+-\mathrm{Th}-)$. As in the judgment session, 2 targets (4 configurations for each) served as familiarization trials and 9 targets as test trials. The 9 test targets appeared in a different random order in each of 4 blocks with the 4 types of configurations roughly counterbalanced across the blocks. The spatial position of the 2 
associates (strong and weak, and taxonomic and thematic for heterogeneous configurations) was counterbalanced across items in each block.

\section{Results}

\section{$\underline{\text { Judgments of associative strength }}$}

At a descriptive level, mean judgments of associative strength reflected fairly the degrees established prior to the experiment. For taxonomic associates, associative strength covaried with category level: $75 \%$ of the strong taxonomic associates $(\mathrm{T}+)$ were basic-level associates and $72 \%$ of the weak taxonomic associates (T-) were superordinate associates. For thematically related pictures, associative strength was more variable but reflected roughly the levels established during the pre-test: $66 \%$ of strongly related pictures $(\mathrm{Th}+)$ and $64 \%$ weakly related pictures (Th-) were predominantly those intended by the experimenters. This result means that the task was generally well understood and that judgments of associative strength appeared to be valid.

\section{Matching task}

The dependent variable was the number of strong associates ("+choices") chosen by age (younger subjects vs older subjects) and configuration (Th+Th-, T+T-, Th+T-, T+Th-). To test a global effect of associative strength, t-tests were first performed against chance for homogeneous configurations at each age. All percentages were significantly greater than 50\% (see Figure 1). This shows that associative strength reliably influenced choices in adults. This global effect did not differ between young and elderly subjects $(\mathrm{p}>.05)$.

\section{Insert Figure 2: mean percentages of "+choices" by age and conditions}

Concerning heterogeneous configurations, "+choices" were still predominant in $\mathrm{Th}+\mathrm{T}-$ configurations (t-tests against 50\% were significant at both ages), but did not differ from chance level in $\mathrm{T}+\mathrm{Th}$ - configurations. Hence, associative strength does not appear as the only factor affecting subjects' performances in the matching task; conceptual preference also plays a role. 
An analysis of variance was then performed with age (younger vs. elderly) as between-subjects factor, and configurations (homogeneous vs. heterogeneous) and type of relation of the strong associate (Th vs. T) as within-subjects factors. The analysis revealed main effects of configuration $[\mathrm{F}(1,53)=34.43, \mathrm{p}<.001]$ and type of relation $[\mathrm{F}(1,53)=77.39$, $\mathrm{p}<.001]$ and an interaction effect between both factors $[\mathrm{F}(1,53)=24.73, \mathrm{p}<.001]$. More "+choices" were produced in homogeneous than in heterogeneous configurations; more "+choices" were thematically than taxonomically related to the target. More importantly, regarding the influence of associative strength and conceptual relation, the strong associate was less frequently chosen in heterogeneous than in homogeneous configurations when it was taxonomic $[\mathrm{F}(1,53)=42.1, \mathrm{p}<.001]$, but chosen equally in both configurations when it was thematic $[F(1,53)=1.22, p>.05]$. No main effect of age was observed $[(F 1,53)=0.18, p>.05]$ and no other interaction was significant.

\section{Discussion}

In this research, we studied whether the salience of categorical associations could explain the differences generally observed between young and elderly adults. We tested the hypothesis of a possible decrease of developmental differences, showing that young and elderly adults were equally sensitive to associative strength between stimuli and type of relation.

Individual judgments were used to build triads in which a target was presented along with a strong and a weak associate (Scheuner et al., 2001, 2004, in press). Results in homogeneous configurations ( 2 thematic or 2 taxonomic associates) indicated that associative strength was a decision basis at both ages since "+choices" were always predominant. However, associative strength was not the only decision basis because "+choices" varied in heterogeneous configurations depending whether the strong associate was taxonomically or thematically related to the target: thematic "+choices" were predominant $(\mathrm{Th}+\mathrm{T}$ configurations) whereas taxonomic "+choices" were not ( $\mathrm{T}+\mathrm{Th}$ - configurations). As revealed by the global analysis, strong thematic associations were predominant over all weak associations, be they thematic or taxonomic, whereas strong taxonomic associations were predominant only over weak taxonomic associations. Therefore, as in young children 
(Scheuner et al., 2004, in press), thematic orientation appeared to influence adults' decisions and to conflict with associative strength in $\mathrm{T}+\mathrm{Th}$ - configurations.

In line with our hypothesis, the pattern of categorical choices was similar for young and older adults. It shows that both groups were influenced by associative strength and type of relation in the same way. According to Lin and Murphy's results (Lin \& Murphy, 2001), data suggest that there is a thematic preference in young adults. In addition, they show that this thematic preference remains stable between 40 and 80 years of age. Our results conflict with the idea that categorical preferences evolve with aging as claimed by some authors (Fontaine \& Toffart, 2000; Smiley \& Brown, 1979). Instead, they support the interpretation that the predominance of taxonomic choices in young adults and their decrease in elderly adults, which have frequently been observed, would reflect an experimental bias regarding the salience of the categorical associations. Indeed, when associative strength is equated at the individual level, no age effect was evidenced. Moreover, according to the results observed in the taxonomic homogeneous configurations, older subjects were able to choose and justify a taxonomic choice in the same way as the young adults.

Our results do not support the interpretation put forward by Annett (1959), Cicirelli (1976) and Denney \& Lennon (1972). Changes in categorical behaviour in old age do not seem to be related to a decline in perceiving and using taxonomic relations. On the contrary, our data support the proposition of Kogan (1974). Moreover, the influence of associative strength observed here could help to reconcile some divergent findings. Differences between young and elderly adults that are usually explained by a cognitive decline or a modification of categorical preferences could be related to stimuli bias.

It could be thought that in matching tasks, as in memory tasks, responses derive from an automatic process based on diffuse activation and from a more controlled comparison process based on the processing of conceptual relations (Collins \& Loftus, 1975; Corson, 1996). The first process refers to the effect of associative strength, whereas the second corresponds to a more controlled selection process aimed at comparing both conceptual relations. Our data show that both processes were at work in this task and, moreover, support the interpretation of a greater availability of thematic than taxonomic relations in adults when "goes best" instructions were provided. In fact, when the strong associate was thematically related to the target, "+choices" were equally frequent in Th+Th- configurations in which 
associative strength was the unique basis of choice and in $\mathrm{Th}+\mathrm{T}$ - configurations in which both associative strength and type of relation could influence choices. Yet, when the strong associate was taxonomically related to the target, "+choices" dominated only in $\mathrm{T}+\mathrm{T}$ configurations, not in $\mathrm{T}+\mathrm{Th}$ - configurations; in these latter configurations, the taxonomic associate strongly related to the target was selected as frequently as the thematic associate weakly related to it. Hence, it seems that thematic orientation can conflict with associative strength. Specifically, the equivalence of choices in $\mathrm{T}+\mathrm{Th}$ - configurations suggests that the activation threshold required to select one associate is reached earlier for thematic than for taxonomic associates, and therefore that thematic relations are more easily available than taxonomic ones in young and elderly subjects in this situation.

In addition, a lack of homogeneity in associative strength across items and/or individuals could explain the inter- and intra-individual variability frequently mentioned in matching tasks. According to this logic, various patterns of responses among young and older adults might result partly from differences in the judgments of associative strength of a given association, whereas within adults variability would stem from mean differences in these judgments across items. Future research should thus focus on the study of patterns of the evolution of associative strength in ageing. More generally, we suggest that age differences do not necessarily reflect a cognitive decline but rather might correspond to behavioural modifications related to different but equally adaptive environmental perceptions.

It is possible to interpret our results with Baltes's (1987) model which distinguishes three broad systems of developmental influences: Age-graded influences, History-graded influences and Non-normative influences. Age-graded influences are defined as biological and environmental determinants that have a fairly strong relationship to chronological age and are, therefore, quite predictable in their temporal course; their direction of influence is similar across individuals. History-graded influences also involve biological and environmental determinants, but they are associated with historical time. Individuals develop within the framework of evolution and culture (the influences of pharmacology on health, the nature of educational opportunities). Non-normative influences differ from individual to individual and represent the idiosyncratic facet of development; they are factors such as unique life experiences or health conditions. Individuals do not have any control over the first two factors but can influence the third. According to Baltes, Reese \& Lipsitt (1980), the relative role of these three types of influence varies throughout life. Non-normative influences would 
continue to increase throughout life, and in old age they would constitute the most important factor in cognitive performance. In this perspective, ageing appears to be an individuation and a personalization process (Fontaine, 1999) and therefore would be partially under our control. Age influences and finally life-history influences would then take effect, these influences being less strongly related to cognitive performance. In summary, this approach regards intellectual ageing as a phenomenon which is not exclusively cognitive since environmental and autobiographical factors play an important role. Our results are consistent with this model because categorical choices evolve with aging in conjunction with judgments of associative strength. It is likely that autobiographical experiences constrain the perception of commonalities and differences between stimuli and thus lead to a modification of judgments of associative strength. To interpret cognitive differences between young and elderly adults in terms of a cognitive decline, it seems necessary to consider the influence of non-normative factors. 


\section{References}

Annett, M. (1959). The classification of instances of four common class concepts by children and adults, British Journal of Educational Psychology, Vol. 29, 3, 223-236.

Baddeley, A. D. (1986).Working memory. London: Oxford University Press.

Baltes, P. B. - (1987) Theorical propositions of life-span developmental psychology : On the dynamics between growth and decline, Developmental Psychology, 23, 611-626.

Baltes, P. B., Reese H. W., Lipsitt L. P. (1980) - Life-span developmental psychology, Annual Review of Psychology, 31, 65-110.

Birren, J.E., Woods, A.M., \& Willams M.V. (1980). Behavioral slowing with age. In L.W. Poon (Ed.), Aging in the 1980's. Washington, DC: American Psychology Association.

Cicirelli, V. G. (1976). Categorization behavior in aging subjects. Journal of Gerontology, Vol. 31, N. 6, 676-680.

Collins A.M., \& Loftus E.F. (1975). A spreading activation theory of semantic processing. Psychological Review, 82, 407-428.

Corson, Y. (1996). Effets de la nature des relations semantiques sur les processus d'activation entre amorces et cibles associativement liees. / Effects of the nature of semantic relationships on the activation processes between primes and associatively linked targets. Canadian Journal of Experimental Psychology, 50, 243-260.

Cramer, P., Eagle, M. (1972). Relationship between conditions of CRS presentation and the category of false recognition errors. Journal of Experimental Psychology, 94, 1-5.

Deak, G., \& Bauer, P. J. (1995). The effects of task comprehension on preschoolers' and adults' categorization choices. Journal of Experimental Child Psychology, 60, 393-427.

Denney, N. W. (1974). Classification abilities in the elderly. Journal of Gerontology, Vol. 29, $\mathrm{N}^{\circ} 3,309-314$.

Denney, N. W., \& Denney, D. R. (1974). Modeling effects on the questioning strategies of the elderly, Developmental Psychology, Vol. 10, N. 3, 458.

Denney, N. W., \& Lennon M. L. (1972). Classification : a comparison of middle and old age, Developemental Psychology, Vol. 7, N. 2, 210-213.

Fontaine, R. (1999). Manuel de Psychologie du vieillissement, Dunod, Paris.

Fontaine, R., \& Toffart, L. (2000). Les prédicteurs des capacités de réserve cognitive chez la personne âgée. In D. Brouillet \& A. Syssau (Eds). Le vieillissement cognitif normal, DeBoeck, Bruxelles.

Kogan, N. (1974). Categorizing and conceptualizing styles in younger and older adults. Human Development, 17, 218-230.

Krackow, E. \& Gordon, P. (1998). Are lions and tigers substitutes or associates? Evidence against slot filler accounts of children's early categorization. Child Development, 69 , 347-354.

Lathey, J. W. (1979). Free recall of nonretarded and EMR children: Associative and categorical bases of clustering. American Journal of Mental Deficiency, 84, 96-99.

La-Heij, W., Dirkx, J., \& Kramer, P. (1990). Categorical interference and associative priming in picture naming. British Journal of Psychology, 81, 511-525.

Lin, E. L., \& Murphy, G. L. (2001). Thematic relations in adults' concepts. Journal of Experimental Psychology : General, Vol. 130, N. 1, 3-28.

Mathews, R. C., Maples, R. C., \& Elkins, R. (1981). Semantic judgments as encoding operations in recall: The encoding of task-relevant and task-irrelevant semantic attributes of words. Journal of General Psychology, 105, 311-320. 
McCauley, C., Weil, C. M., \& Sperber, R. D. (1976). The development of memory structure as reflected by semantic-priming effects. Journal of Experimental Child Psychology, 22, 511-518.

Nation, K., \& Snowling, M. J. (1999). Developmental differences in sensitivity to semantic relations among good and poor comprehenders: Evidence from semantic priming. Cognition, 70, 1-13.

Nelson, K. (1983). The derivation of concepts and categories from events representations. In E. K. Scholnick (Ed.). New trends in conceptual representations: Challenges to Piaget's theory. Hillsdale (N. J.): Erlbaum, 129-149.

Olver, R. R. \& Hornsby, J. R. (1966). On equivalence. In J. S. Bruner, R. R. Olver, \& P. M. Greenfield (Eds.), Studies in cognitive growth. New-York: Wiley.

Pennequin, V., \& Fontaine, R. (2000). Training for older adults : the example of class inclusion, Journal of Adult Development, Vol.2, $N^{\circ} 2 ., 68-88$.

Rosch, E., Mervis, C. B., Gray, W. D., Johnson, D. M. \& Boyes-Braem, P. (1976). Basic objects in natural categories. Cognitive Psychology, 8, 382-439.

Ross, B.H., \& Murphy, G.L. (1999). Food for thought: Cross-classification and category organization in a complex real-world domain. Cognitive psychology, 38, 495-553.

Salthouse, T.A. (1985). Speed of behavior and its implications for cognition. In J.E. Birren \& K.W. Schaie (Eds.), Handbook of the Psychology of Aging (2nd ed.). New York: Van Nostrand Reinhold.

Salthouse, T.A. (1996). The processing-speed theory of adult age differences in cognition. Psychological Review, 103, 403-428.

Schaie, K. W. (1993). The Seattle longitudinal studies of adult intelligence. Current Directions in Psychological Science, 2, 171-175.

Schaie, K. W. (Ed.). (1983). Longitudinal studies of adult psychological development. New York: Guilford Press.

Scheuner, N., Bonthoux, F., Cannard, C., \& Blaye, A. (2001). Influence des associations spécifiques sur les choix d'appariements schématiques et taxonomiques à 4 et 6 ans. In A. Flieller, C. Bocéréan, J.-L. Kop, E. Thiébault, A.-M. Toniolo and J. Tournois (Eds.), Questions de psychologie différentielle. (pp. 209-214) Rennes: Presses Universitaires de Rennes.

Scheuner, N., Bonthoux, F., Cannard, C., \& Blaye, A. (2004 sous presse). The role of associative strength and conceptual relations in matching tasks in 4- and 6-year-old children. International Journal of Psychology, 39.

Siegler, R. S. (1997). Concepts and methods for studying cognitive change. In E. Amsel \& K. A. Renninger (Eds.), Change and Development. Issues of theory, method, and application, Mahwah (N. J.), L. Erlbaum, 77-97.

Sloutsky, V. M. (2003). The role of similarity in the development of categorization. Trends in Cognitive Sciences, 7, 246-251.

Smiley, S. S., \& Brown, A. L. (1979). Conceptual preference for thematic or taxonomic relations: A nonmonotonic age trend from preschool to old age. Journal of Experimental Child Psychology, 28, 249-257. 


\section{Target : a dog}

another dog

a guinea pig

a snake

Appendix 1 - Example of a given target with associates which correspond a priori to 3 hierarchical levels of taxonomic associative strength 

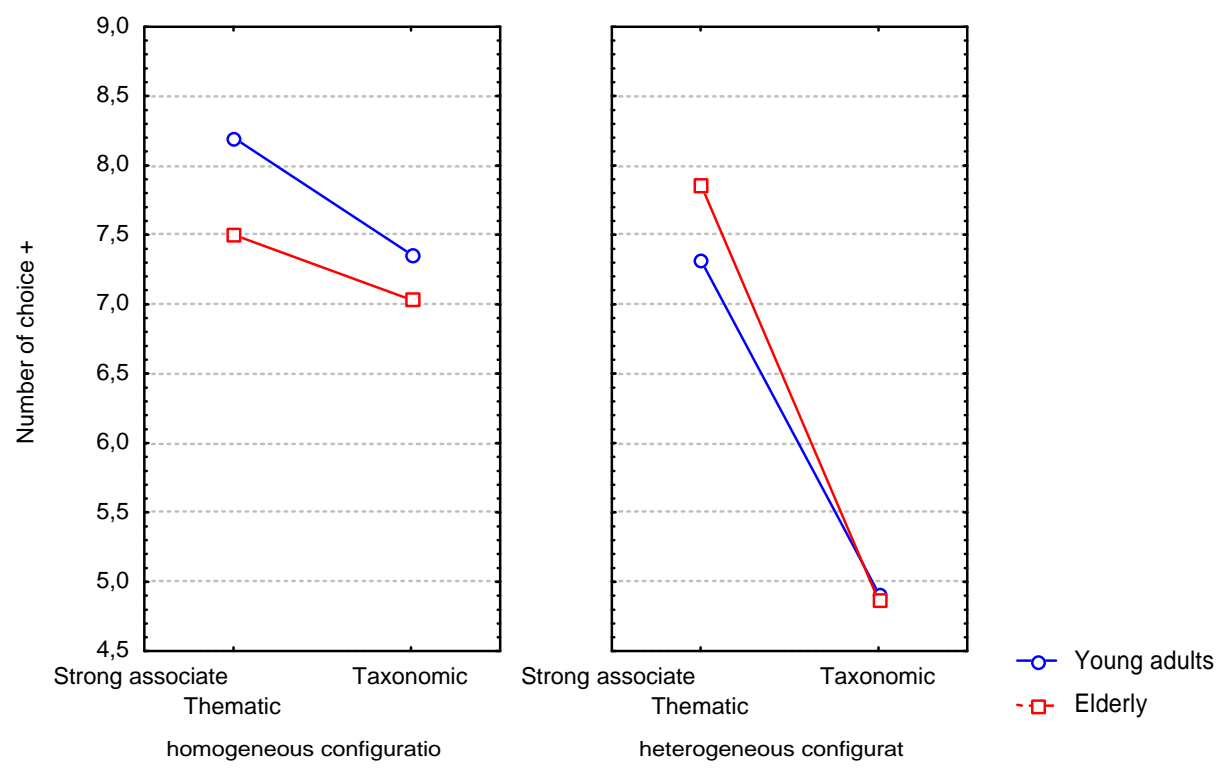

Figure. 2. Mean number of "choices + " by age and conditions 